\title{
Specific volume and compressibility of bilayer lipid membranes with incorporated $\mathrm{Na}, \mathrm{K}$-ATPase
}

\author{
Tibor Hianik ${ }^{1}$, Peter Rybár ${ }^{1}$, Roland Krivánek ${ }^{1}$, Mária Petríková ${ }^{1}$, Milena Roudna $^{2}$ \\ and Hans-Jürgen Apell ${ }^{2}$ \\ ${ }^{1}$ Faculty of Mathematics, Physics and Informatics, Comenius University, Mlynska dolina F1, 84248 Bratislava, Slovakia \\ ${ }^{2}$ Department of Biology, University of Konstanz, D-78464 Konstanz, Germany
}

\begin{abstract}
Ultrasound velocimetry and densitometry methods were used to study the interactions of the $\mathrm{Na}, \mathrm{K}$-ATPase with the lipid bilayer in large unilamellar liposomes composed of dioleoyl phosphatidylcholine (DOPC). The ultrasound velocity increased and the specific volume of the phospholipids decreased with increasing concentrations of protein. These experiments allowed us to determine the reduced specific apparent compressibility of the lipid bilayer, which decreased by approx. $11 \%$ with increasing concentrations of the $\mathrm{Na}, \mathrm{K}$-ATPase up to an ATPase/DOPC molar ratio $=2 \times 10^{-4}$. Assuming that ATPase induces rigidization of the surrounding lipid molecules one can obtain from the compressibility data that 3.7 to 100 times more lipid molecules are affected by the protein in comparison with annular lipids. However, this is in contradiction with the current theories of the phase transitions in lipid bilayers. It is suggested that another physical mechanisms should be involved for explanation of observed effect.
\end{abstract}

Key words: Na,K-ATPase - Phosphatidylcholine liposomes - Protein-lipid interactions - Densitometry - Ultrasound velocimetry - Membrane compressibility

\section{Introduction}

Biophysical studies of the mechanisms of protein-lipid interactions suggest the existence of annular lipids surrounding the integral membrane proteins (Lee 2003). These lipid molecules are, however, not simply adjacent to the protein, but exhibit in general fast exchange with bulk lipids (Marsh and Horvath 1998). At the same time the lipid packing affects also the protein-lipid interactions (Karlovská et al. 2006; Sanchez et al. 2010). Due to inhomogeneities of the protein surface, the surrounding lipids tend to adapt their conformation in order to gain optimal contact with the hydrophobic surface of the protein. It has been established that in the case of $\mathrm{Ca}^{2+}$-ATPase approximately 30 lipid molecules surround the protein in an annulus-like ring (Toyoshima et al. 2000). The lipid environment affects the functioning of ATPases. Starling el al. (1995) found differences in the rate of dephos-

Correspondence to: Tibor Hianik, Faculty of Mathematics, Physics and Informatics, Comenius University, Mlynska dolina F1, 84248 Bratislava, Slovakia

E-mail: tibor.hianik@fmph.uniba.sk phorylation of the Ca-ATPase depending on the thickness of the bilayer, with the slowest rate for $\operatorname{di}(\mathrm{C} 24: 1)$ PC bilayers. The role of annular lipids in the protein-lipid interactions has been reviewed recently in paper by Ernst et al. (2010). Beyond existing observations the question arises whether only annular phospholipids are involved in protein-lipid interactions, or whether an extended environment of the lipid bilayer is affected by the presence of an integral protein. In addition, it is necessary to analyze how the properties of the lipid bilayers are altered in close proximity of the proteins compared to the unperturbed lipid bilayer.

Due to problems with a functional isolation and purification of integral membrane proteins, so far, the mechanisms of protein-lipid interactions were studied only with a few integral proteins (for review, see Lee 2003). The most detailed study was performed with bacteriorhodopsin (BR), which is one of the most stable proteins. It participates as proton pump in the energy transduction of the purple membranes of Halobacterium salinarum (previously Halobacterium halobium) (Piknova et al. 1993). In particular, fluorescencespectroscopic studies performed by Rehorek et al. (1985) showed that as a result of conformational changes of BR the 
ordering of the lipid bilayer increases, and a propagation of conformational energy occurs over the distance of more than $4.5 \mathrm{~nm}$. Mechanical properties of the membranes are also very sensitive to the conformation changes of proteins in lipid bilayers. The influence of BR on the structural state of regions of planar bilayer lipid membranes (BLMs) was detected by means of the elasticity modulus $E_{\perp}$ (Hianik and Vozár 1985). It has been estimated that the area of a lipid bilayer with an altered structure surpasses $2800 \mathrm{~nm}^{2}$ per one BR trimer. Moreover, a considerable increase of $E_{\perp}$ took place as result of the light-induced conformational changes of BR. Substantial decrease of volume compressibility of liposomes containing BR was demonstrated by the ultrasound velocimetry method (Hianik et al. 1993). In particular, it was shown that one BR trimer is able to change the structural state of the lipid bilayer of large unilamellar liposomes composed of dipalmitoyl phosphatidylcholine (DPPC) within a diameter of approximately $100 \mathrm{~nm}$. The existence of large distorted regions around BR was confirmed also by theoretical studies (Hianik and Passechnik 1995).

The mechanism of interaction between the Na,K-ATPase and phospholipids has been studied to a lesser extend. The focus was concentrated on how phospholipid structure and composition affect the functional properties of the protein, including transport rate, ion binding and turnover. A higher transport rate was observed when the ion pumps were reconstituted in membranes of $\operatorname{di}(18: 1) \mathrm{PC}, \operatorname{di}(20: 1) \mathrm{PC}$ and $\operatorname{di}(22: 1) \mathrm{PC}$, whereas in $\operatorname{di}(14: 1) \mathrm{PC}$ and di(16:1)PC the enzyme was almost inactive (Marcus et al. 1986). In certain cases also specific lipids have been found to be an important factor for functioning the integral protein. For example $\mathrm{Na}, \mathrm{K}-\mathrm{ATPase}$ interacts specifically with cardiolipin (Esmann and Marsh 2006). ATPase activity was considerably enhanced in the presence of relatively high amount of cholesterol (40 mol\%) (Cornelius et al. 2003).

In this work we applied the method of densitometry and ultrasound velocimetry to determine changes of specific volume and compressibility of the lipid bilayer with incorporated $\mathrm{Na}, \mathrm{K}$-ATPase.

\section{Materials and Methods}

\section{Chemicals and preparation of proteoliposomes containing $\mathrm{Na}, \mathrm{K}$-ATPase}

ATP (disodium salt) was obtained from Boehringer (Mannheim, Germany). Dioleoyl phosphatidylcholine (DOPC, molecular weight $768.15 \mathrm{~g} / \mathrm{mol}$ ) was ordered from Avanti Polar Lipids (USA). All other reagents were of the highest grade commercially available.

$\mathrm{Na}, \mathrm{K}-\mathrm{ATPa} e$ was prepared from outer medulla of rabbit kidneys using procedure C of Jørgensen (1974). The specific activity of the purified microsomal preparation was $\sim 2200$ $\mu \mathrm{mol} \cdot \mathrm{P}_{\mathrm{i}}$ per hour and $\mathrm{mg}$ protein at $37^{\circ} \mathrm{C}$. Molecular weight of ATPase was $147 \mathrm{kDa}$ (Ivashchuk-Kienbaum and Apell 1994). Unilamellar liposomes were prepared from cholatesolubilized protein and lipids by a dialysis method (Apell et al. 1985) with various protein/lipid ratios. Briefly, the protein has been treated with $1 \% \mathrm{Na}$-cholate as detergent in the buffer to dissolve the membrane fragments. This allows the reconstitution of the $\mathrm{Na}, \mathrm{K}$-ATPase in vesicles, when mixed with lipid $(18 \mathrm{mg} / \mathrm{ml})$ dissolved in the detergent Na-cholate $(10 \mathrm{mg} / \mathrm{ml})$. Thereafter the mixture was dialyzed against the 1000 -fold buffer volume to remove the detergent. For dialysis a $120 \mathrm{~mm}$ long dialysis tube (Visking 8/32, Serva, Cat. No. 44104) closed with two clamps has been used. Dialysis was performed at $4^{\circ} \mathrm{C}$ in buffer containing $30 \mathrm{mM}$ imidazole, $1 \mathrm{mmol} / \mathrm{l} \mathrm{EDTA,} 2.5 \mathrm{mmol} / \mathrm{MgSO}_{4}, 2.5 \mathrm{mmol} / 1 \mathrm{Na}_{2} \mathrm{SO}_{4}$, and $25 \mathrm{mmol} / \mathrm{I} \mathrm{K}_{2} \mathrm{SO}_{4}, \mathrm{pH}$ 7.2. After at least 72 hours of dialysis the proteoliposome solution was removed from the tubing. This method allowed us to obtain unilamellar vesicles with a diameter of about $100 \mathrm{~nm}$ independently on the concentration of the protein. This has been approved earlier by electron microscopy and dynamic laser-light scattering (Skriver et al. 1980; Anner et al. 1984; Marcus et al. 1986). These studies clearly showed that multilamellar vesicles or cubic phases of lipids were never present in a sample of liposomes. The content of detergent in a sample after 72 hours of dialysis was much lower than $1 \%$ and has been below the sensitivity of HPLC method (Alpes et al. 1988). The liposomes without protein were prepared exactly by the same method as that with protein. The only difference was that in the case of the pure lipid vesicles the lipid solution was diluted with protein-free buffer instead of protein-containing buffer.

The lipid concentration of the solution was determined by the Phospholipid B test (Wako Pure Chemical Industries, Ltd. Osaka, Japan). Briefly, the phosphatidylcholines are hydrolyzed to set free choline by phospholipase $\mathrm{D}$. The released choline is subsequently oxidized to betaine by choline oxidase with the simultaneous production of hydrogen peroxide. The hydrogen peroxide, which is produced stoichiometrically, couples oxidatively 4 -aminoanti-pyrine and phenol to yield a chromogen with a maximum absorption at $\lambda=505 \mathrm{~nm}$. To calibrate the test a standard solution was prepared which contains $0.54 \mathrm{mg} / \mathrm{ml}$ choline chloride and $0.1 \%$ phenol as precisely as possible (errors below $1 \%$ ). This corresponds to a solution of $3 \mathrm{mg} / \mathrm{ml}$ phosphatidylcholine. The calibration curve for the micro assay was taken with appropriate aliquots of the standard solution corresponding amounts of phosphatidylcholine between 0 and $50 \mu \mathrm{g}$ (absolute). The calibration curve was always linear and reliable. When known concentrations of phosphatidylcholine lipid were tested, the agreement between the known amount of lipid and the amount determined by the Wako test was 
always better than $5 \%$, which includes all the uncertainties of pipetting solutions and reading the amount from the calibration curve. We determined the lipid contents of the samples always threefold, and the agreement of the result was always better than $5 \%$.

Protein concentration has been determined by the Markwell method (Olson and Markwell 2007), which is a modification of the classical Lowry method (Lowry et al. 1951). The difference consists only in addition of $1 \%$ sodium dodecyl sulphate (SDS). This method is more suitable for determination of protein concentration in vesicles since the SDS dissolves the vesicles and therefore protein determination is more exact. All determinations were performed with aliquots, contained higher concentration of lipids (approx. $10 \mathrm{mg} / \mathrm{ml}$ ) and at least $10 \mu \mathrm{g} / \mathrm{ml}$ protein. As a control we always measured also a calibration curve (with bovine serum albumin (BSA) in parallel and took these as reference for the measured absorption values. The protein/lipid ratio was varied between $1: 175000$ and $1: 5250$. At the end of the dialysis the lipid concentration was found to be between 8 and $10 \mathrm{mg} / \mathrm{ml}$. These solutions were diluted with buffer to obtain concentrations of about $5 \mathrm{mg} / \mathrm{ml}$ for the experiments in the ultrasound equipment. In order to increase the precision of the data, in part the lipid and protein concentration was determined again after the ultrasound experiments.

\section{Measurement of ultrasound velocity and density}

The measurement of ultrasound velocity allows us to evaluate the elastic properties of aqueous media and suspensions such as liposomes (Halstenberg et al. 1998; Hianik et al. 1998), lipoproteins (Hianik et al. 1999) or cell surface proteins (Hianik et al. 1997) based on a simple relationship:

$$
\beta_{S}=\frac{1}{\rho \cdot u^{2}}
$$

where $\beta_{S}, \rho$, and $u$ are the adiabatic compressibility, the density, and the sound velocity of the suspension, respectively. Thus, by measuring the changes of sound velocity and density, one can determine the changes of compressibility (Hianik et al. 1999).

Ultrasound velocity was measured using a fixed-path differential velocimeter consisting of two almost identical acoustic cavity resonators (Sarvazyan 1991) operated at frequencies around 7.2 MHz. The resonance frequencies of the cells were measured using a computer-controlled network analyzer (USAT, USA). The sample volume was 0.7 $\mathrm{ml}$. The resonator cells were equipped with magnetic stirrers to ensure homogeneously dispersed samples during the measurements. One resonator contained the vesicle solution whereas the other one was filled with the same buffer solution ( $1 \mathrm{mmol} / \mathrm{l} \mathrm{EDTA,} 2.5 \mathrm{mmol} / \mathrm{l} \mathrm{MgSO}_{4}, 2.5 \mathrm{mmol} / \mathrm{l} \mathrm{Na}_{2} \mathrm{SO}_{4}$, and $25 \mathrm{mmol} / \mathrm{K} \mathrm{K}_{2} \mathrm{SO}_{4}$, $\mathrm{pH}$ 7.2) without vesicles as reference. When starting a series of measurements, first the resonance frequencies of both resonators were compared by measuring both cells with identical reference liquid. As the energy density of the sonic signal was small throughout (the pressure amplitude in the ultrasonic wave was less than $10^{3} \mathrm{~Pa}$ ), any effects of the sound wave on the structural properties of the vesicles were avoided. In general, ultrasonic velocimetry allows the determination of the sound velocity $[u]$ or rather its concentration-dependent increments (Sarvazyan 1982) as defined by the equation:

$$
[u]=\frac{u-u_{0}}{u_{o} c}
$$

where $c$ is the solute concentration in $\mathrm{mg} / \mathrm{ml}$, and the subscript " 0 " refers to the solvent (buffer). The value $[u]$ can be directly determined from the changes of resonance frequencies $f$ and $f_{0}$ of both resonators ( $f$ is resonance frequency of the sample, and $f_{0}$ that of the reference buffer):

$$
[u]=\frac{u-u_{0}}{u_{0} c}=\frac{f-f_{0}}{f_{0} c}(1+\gamma)
$$

(the coefficient fulfills the condition $\gamma<<1$ (Sarvazyan and Chalikian 1991) and can be neglected in the calculations).

A high precision densitometric system (DMA 60 with two DMA 602 M sample chambers, Anton Paar KG, Graz, Austria) operating according to the vibrating tube principle (Kratky et al. 1973) was used to determine the density $\rho$ of the vesicle solution. Apparent specific partial volumes $\varphi_{V}$ have been calculated from the density data using the relation

$$
\varphi_{V}=\left[1-\frac{\rho-\rho_{0}}{c}\right] \frac{1}{\rho_{0}}=\frac{1}{\rho_{0}}-[\rho]
$$

where the subscript 0 refers again to the reference solvent and $[\rho]=\left(\rho-\rho_{0}\right) /\left(\rho_{0} c\right)$ denotes the concentration increment of density. The temperature of the cells was controlled to within $\pm 0.02^{\circ} \mathrm{C}$ with a Lauda RK 8 CS ultra-thermostat (Lauda, Germany).

The determination of the specific volume in addition to the sound-velocity concentration increment allowed the estimation of the reduced specific apparent compressibility $\varphi_{K} / \beta_{0}$ of the vesicles, which is based on the following equation:

$$
\frac{\varphi_{K}}{\beta_{0}}=-2[u]-\frac{1}{\rho_{0}}+2 \varphi_{V}
$$

where $\beta_{0}$ is the coefficient of the compressibility and $\rho_{0}$ is the buffer density (Sarvazyan 1991). The value of $\varphi_{K} / \beta_{0}$ indicates the volume compressibility of the vesicles relative to the buffer. 


\section{Experimental errors}

The accuracy in determination of the concentration of lipids and $\mathrm{Na}, \mathrm{K}$-ATPase was better than $5 \%$. The temperature of the measuring chambers was controlled in a range of $\pm 0.02^{\circ} \mathrm{C}$. The relative error in the resonance frequencies of the ultrasonic resonator chambers was $\pm 5 \mathrm{~Hz}$ and less then $\pm 10^{-3} \mathrm{ml} / \mathrm{g}$ for $[u]$ and $\varphi_{V}$, respectively. The error in the determination of density was less than $\pm 10^{-3} \mathrm{~g} / \mathrm{ml}$. Each series of experiments was performed at least three times.

\section{Results}

Measurements of ultrasound velocity and density allowed us to estimate the mechanical properties of lipid bilayer of vesicles and their modification caused by protein-lipid interactions (Hianik et al. 1993; Rybár et al. 2007). We studied the mechanical properties of proteoliposomes at various molar ratios of ATPase/lipid. We used vesicles composed of DOPC that has been shown to be a lipid in which the $\mathrm{Na}, \mathrm{K}$-ATPase revealed optimal activity in the presence of ATP (Marcus et al. 1986). Figure 1 shows the plot of the concentration increment of the sound velocity, $[u]$ (see Eq. 2), as function of the temperature for liposomes without ATPase and for liposomes of molar ratios of ATPase/DOPC = 1: 52500 and $1: 5250$. It can be seen that the value $[u]$ decreases monotonously with increasing temperatures. This may be interpreted as a decrease of lipid-bilayer ordering, which can be related to an increased conformational freedom of the phospholipids hydrocarbon chains with increasing temperature. The hydration shell surrounding both lipids and proteins becomes,

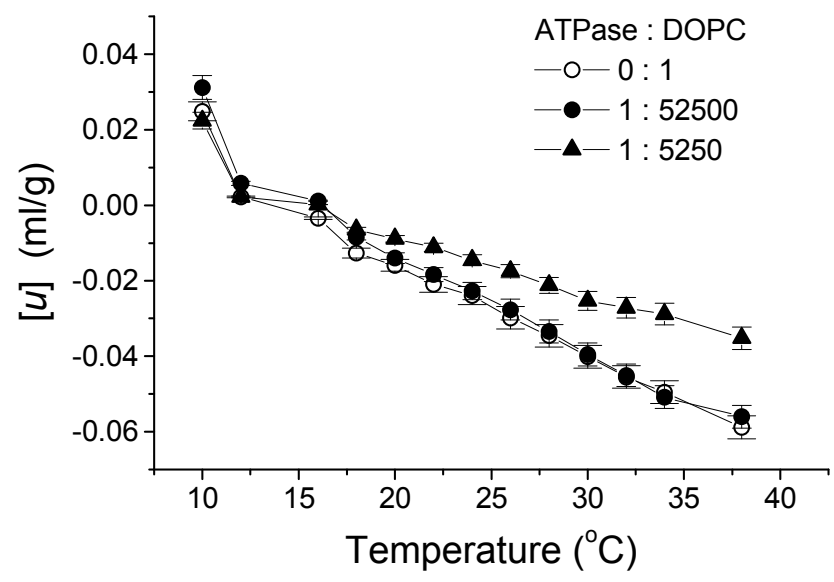

Figure 1. Concentration increment of sound velocity $[u]$ versus temperature for aqueous suspension of vesicles from DOPC with different ATPase/DOPC molar ratios: $0: 1 ; 1: 52500 ; 1$ : 5250. Results are mean \pm S.D. obtained from 3 independent experiments.

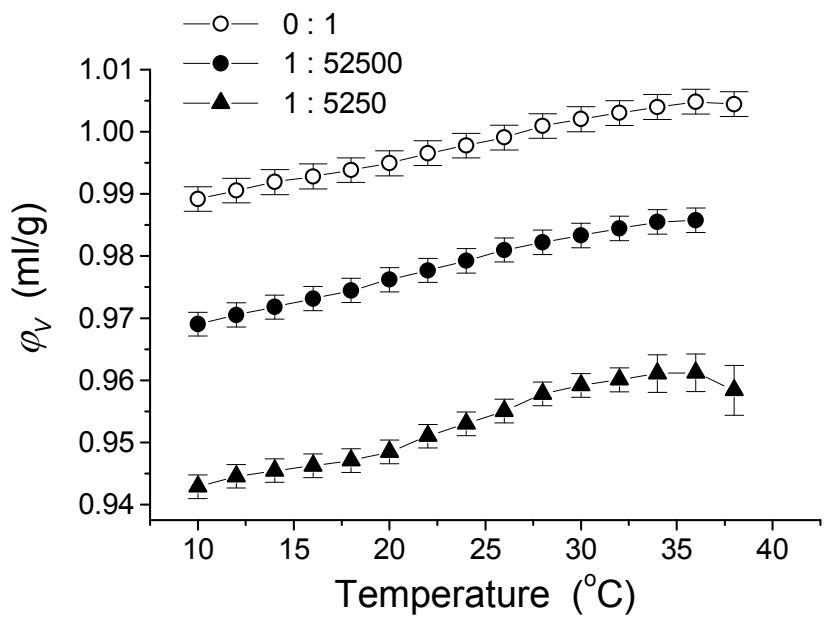

Figure 2. Specific volume $\varphi_{V}$ versus temperature for aqueous suspension of vesicles from DOPC with different ATPase/DOPC molar ratios: $0: 1 ; 1: 52500 ; 1: 5250$. Results are mean \pm S.D. obtained from 3 independent experiments.

however, also more compressible with increasing temperature. Therefore, this contribution should also be taken into account. It can be seen from the Figure 1 that the $[u]$ values of liposomes with ATPase and DOPC differ remarkably only at higher temperatures. However, the influence of the content of the protein on $[u]$ value is not uniform when compared with unmodified liposomes. At lower ATPase concentration (ATPase/DOPC $=1: 52500$ ) the value of $[u]$ is similar to those for liposomes without ATPase. However, at the higher ATPase concentration (ATPase/DOPC $=1: 5250$ ), $[u]$ is higher than in unmodified liposomes.

Because the changes of $[u]$ include changes in compressibility of both the bilayer and the hydration shell, further analysis of the mechanical membrane properties requires the determination of changes of the specific volume of liposomes. This is possible by measuring the density in the proteoliposome suspensions. It allowed us to determine the specific volume $\varphi_{V}$ of the lipid bilayer (see Eq. 4), and its changes with temperature and with different ATPase/DOPC molar ratios. The plot of $\varphi_{V}$ as function of temperature is presented in Figure 2 for various molar ratio of ATPase/DOPC. It can be seen that $\varphi_{V}$ increases with temperature for unmodified liposomes as well as for that with different content of ATPase. The value of $\varphi_{V}$ for unmodified liposomes is in good agreement with previously reported results (Marsh 1990; Hianik et al. 1998). In addition, with increasing contents of ATPase in the vesicles the specific volume decreases. The lower specific volume of proteoliposomes in comparison with unmodified membranes may indicate a more compact structure of lipid bilayer in the presence of the ATPase.

Applying the values $[u]$ and $\varphi_{V}$ in Eq. (5) it is possible to determine the reduced apparent specific compressibility of 
the lipid bilayer, $\varphi_{K} / \beta_{0}$. The plot of the $\varphi_{K} / \beta_{0}$, as function of temperature for unmodified vesicles of DOPC and for proteoliposomes with various content of ATPase is presented on Figure 3. We can see that the specific compressibility increases monotonously with increasing temperature for all systems studied. This behavior is expected and agrees well with our previous studies (Hianik et al. 1998). The increase of the specific compressibility reflects the increased disorder of the liposomes (mostly of the hydrophobic phase of the lipid bilayer) and of an increase of the compressibility of the hydrated shell with increasing temperature. The monotonous change of the specific compressibility reflects the liquid-crystalline state of the bilayer of DOPC in the temperature range studied. The content of ATPase affects substantially the values of $\varphi_{K} / \beta_{0}$. With increasing contents of $\mathrm{Na}, \mathrm{K}$-ATPase the compressibility decreases. This behavior reveals a higher ordering of the lipid bilayer with increasing contents of protein. The decrease of compressibility of the lipid bilayer with ATPase concentration is clearly demonstrated in Figure 4 , where the plot of $\varphi_{K} / \beta_{0}$ is presented as function of the molar ratio ATPase/DOPC at two temperatures, $26^{\circ} \mathrm{C}$ (curve 1 ) and $38^{\circ} \mathrm{C}$ (curve 2). At the higher temperature the changes of $\varphi_{K} / \beta_{0}$ as function of the ATPase contents are closer to a linear behavior. Thus, the results obtained revealed that liposomes containing ATPase are characterized by lower specific volume and lower apparent specific compressibility when compared with unmodified liposomes. Increased contents of ATPase resulted in a decrease of both specific volume and compressibility. We can assume that the ATPase considerably affects the specific volume and compressibility of the surrounding lipid bilayer of the liposomes.

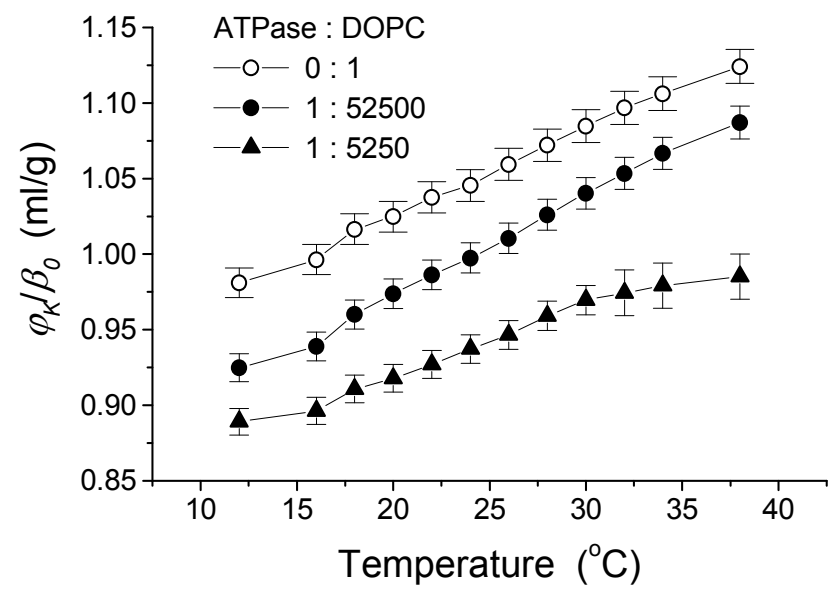

Figure 3. Apparent specific compressibility $\varphi_{K} / \beta_{0}$ versus temperature for aqueous suspension of vesicles from DOPC with different ATPase/DOPC molar ratios: $0: 1 ; 1: 52500 ; 1: 5250$. Results are mean \pm S.D. obtained from 3 independent experiments.

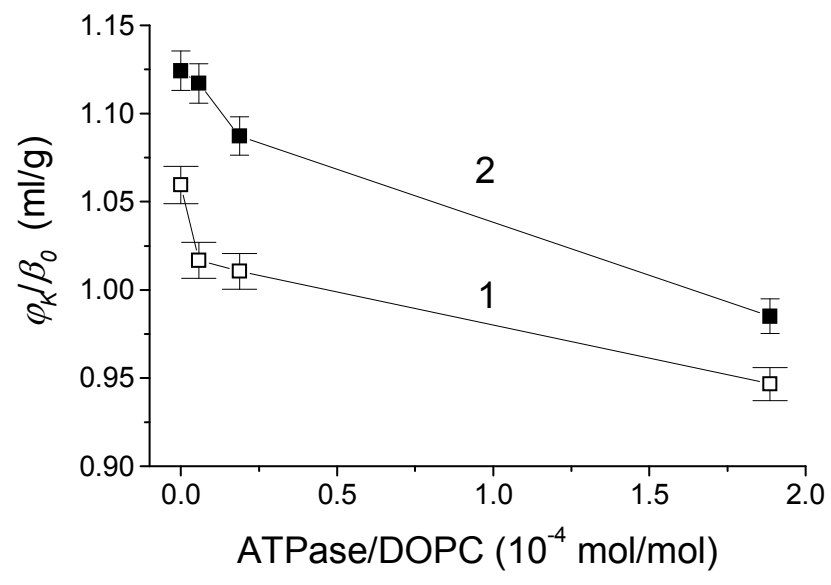

Figure 4. Apparent specific compressibility $\varphi_{K} / \beta_{0}$ plotted as function of the molar ratio ATPase/DOPC at two temperatures, $26^{\circ} \mathrm{C}$ (1) and $38^{\circ} \mathrm{C}(2)$. Results are mean \pm S.D. obtained from 3 independent experiments.

Thus, the important results obtained can be summarized as follows: the enhancement of the ATPase contents in the vesicles led to an increase of the increment of ultrasound velocity $[u]$, a decrease of the specific volume and a decrease of the reduced specific apparent compressibility.

\section{Discussion}

The concentration increment of sound velocity as well as the specific volume, and consequently, also the compressibility are additive and integral parameters. This means that if, for example, a protein molecule is incorporated into the lipid bilayer, the overall reduced specific apparent compressibility $\varphi_{K} / \beta_{0}$ will be composed of the sum of the three respective components of the membrane: 1) of the undisturbed lipid bilayer $\left.\left(\varphi_{K} / \beta_{0}\right)_{L}, 2\right)$ of the altered part of the bilayer caused by protein-lipid interactions $\left(\varphi_{K} / \beta_{0}\right)_{\mathrm{LB}}$ as well as 3$)$ of the protein molecule itself, $\left(\varphi_{K} / \beta_{0}\right)_{\mathrm{P}}$. In addition, the contribution of the hydration shell $\left(\varphi_{K} / \beta_{0}\right)_{\mathrm{H}}$, to the overall compressibility should also be taken into account. Therefore, the overall specific, apparent adiabatic compressibility of proteoliposomes is given by the equation:

$$
\varphi_{K} / \beta_{0}=\left(\varphi_{K} / \beta_{0}\right)_{\mathrm{L}}+\left(\varphi_{K} / \beta_{0}\right)_{\mathrm{LP}}+\left(\varphi_{K} / \beta_{0}\right)_{\mathrm{P}}+\left(\varphi_{K} / \beta_{0}\right)_{\mathrm{H}}
$$

The hydration term is negative at relatively low temperatures, while the other terms are positive. Therefore, the overall value of the reduced specific apparent compressibility could be positive or negative depending on the degree of hydration and on temperature. For example, at $20^{\circ} \mathrm{C}$ the compressibility of globular proteins is in the range $0.05-0.15 \mathrm{ml} / \mathrm{g}$, while 
for more hydrated fibrilar proteins the values of apparent compressibility are in the range -0.1 to $0.75 \mathrm{ml} / \mathrm{g}$ (Sarvazyan and Kharakoz 1977). The value of the overall apparent compressibility is therefore a sensitive indicator of the structural and conformational state of the protein. We will therefore analyze the possible contribution of above mentioned terms to the compressibility of proteoliposomes.

We have shown that the coefficient of reduced apparent specific compressibility decreases with an increasing ATPase/DOPC ratio. This effect can be related to several processes: 1 . Due to considerably smaller compressibility of proteins in comparison with the compressibility of a lipid bilayer, the decrease of the compressibility will be caused by an increasing number of protein molecules in a membrane, arising from the additive rule mentioned above. 2 . Since the ATPase is composed not only from a hydrophobic membrane domain, but also from hydrophilic (cytosolic part exposed to the electrolyte), the latter is hydrated, and the decrease of the overall compressibility can possibly be related also to an increased hydration. 3. The ATPase strongly interacts with surrounding lipids, and as a consequence, the ordering of the lipid bilayer increases. The above-mentioned possibilities have to be estimated and discussed.

\section{Effect of the compressibility of the protein}

The adiabatic compressibility of proteins depends on the degree of their hydration. For example, at $20^{\circ} \mathrm{C}$ the compressibility of human serum albumin (globular protein) is approximately $0.13 \mathrm{ml} / \mathrm{g}$, while the compressibility of fibrilar proteins, e.g. rabbit myosin, is negative: $-0.2 \mathrm{ml} / \mathrm{g}$ (Sarvazyan and Kharakoz 1977). In our recent study we showed that the reduced apparent specific compressibility of native sarcoplasmic reticulum isolated from rabbit skeletal muscles which contained Ca-ATPase was about $-0.46 \mathrm{ml} / \mathrm{g}$ at $25^{\circ} \mathrm{C}$ (unpublished data). The value of the apparent adiabatic compressibility for liposomes with even the highest amount of Na,K-ATPase (molar ratio ATPase/DOPC $=1: 5250$ ) was positive over the whole temperature range studied (Fig. 3). This suggests that the structure of the Na,K-ATPase is rather compact, and that the surface of hydration shell is lower compared to Ca-ATPase. Let us assume that the compressibility of the liposomes is composed of two parts: lipid bilayer and the protein. Then the overall normalized apparent specific compressibility $\varphi_{K} / \beta_{0}$ will be given by equation (Hianik and Passechnik 1995):

$$
\varphi_{K} / \beta_{0}=s\left(\varphi_{K} / \beta_{0}\right)_{\mathrm{L}}+(1-\mathrm{s})\left(\varphi_{K} / \beta_{0}\right)_{\mathrm{P}}
$$

where $\left(\varphi_{K} / \beta_{0}\right)_{\mathrm{L}}$ and $\left(\varphi_{K} / \beta_{0}\right)_{\mathrm{P}}$ are the normalized apparent specific compressibilities of the lipid bilayer and the protein, respectively, $s$ is the relative area occupied by the lipid bilayer and $1-\mathrm{s}$ that of the protein. The cross-sectional area of $\mathrm{Na}, \mathrm{K}-$ ATPase estimated on the base of electron microscopy is approx.
$48.7 \mathrm{~nm}^{2}$ (Hebert et al. 2003). The area $\mathrm{S}_{\mathrm{L}}$ occupied by one phospholipid molecule in a liquid-crystalline state is approx. $0.7 \mathrm{~nm}^{2}$ (Marsh 1990). Then, for the molar ratio ATPase/ DOPC $=1: 5250$ the relative area occupied by lipids will be $s=$ $1-2 \mathrm{mS}_{\mathrm{P}} / \mathrm{S}_{\mathrm{L}}=1-2(1 / 5250) \cdot(48.7 / 0.7)=0.973(\mathrm{~m}$ is the molar fraction of ATPase/lipid, $S_{L}$ and $S_{P}$ is the area occupied by lipid and protein, respectively. The coefficient 2 is due to the pair of the phospholipids in a bilayer). The relative area occupied by protein is: $1-s=0.027$. Using Eq. (7) and the measured value of $\left(\varphi_{K} / \beta_{0}\right)_{\mathrm{L}}=1.12 \mathrm{ml} / \mathrm{g}\left(\right.$ at $\mathrm{T}=38^{\circ} \mathrm{C}$ ) it is possible to estimate the apparent adiabatic compressibility of the protein, applying a value of $\left(\varphi_{K} / \beta_{0}\right)=0.986 \mathrm{ml} / \mathrm{g}$ at this temperature, one obtains from Eq. (7): $\left(\varphi_{K} / \beta_{0}\right)_{\mathrm{P}}=-3.84 \mathrm{ml} / \mathrm{g}$. Thus, the compressibility of the protein could explain the decrease of the overall compressibility of the liposomes with an increased number of protein molecules. The estimated value of $\left(\varphi_{K} / \beta_{0}\right)_{P}$ is, however, negative and considerably lower than the compressibility of the fibrilar and globular proteins investigated so far (Sarvazyan and Kharakoz 1977; Hianik et al. 2006). The Na,K-ATPase is composed of two subunits. The alpha subunit $(\sim 113 \mathrm{kDa})$ binds ATP, and sodium and potassium ions, and it contains the phosphorylation site. The smaller beta subunit, a glycoprotein $(\sim 35 \mathrm{kDa})$, has yet unknown functional properties but it is necessary for enzyme functioning (Jørgensen et al. 2003). The substantial part of the $\mathrm{Na}, \mathrm{K}-\mathrm{ATP}$ ase is anchored in the hydrophobic part of the membrane. Therefore, it could be expected that the value $\left(\varphi_{K} / \beta_{0}\right)_{\mathrm{P}}$ should be positive like that for globular proteins (Sarvayzan and Kharakoz 1977; Kharakoz 2000). Thus, it seems to be unlikely that the observed changes of apparent specific compressibility are related exclusively to that of the proteins, but rather to the compressibility of proteolipid complexes.

\section{Effect of hydration}

The decrease of the reduced apparent specific compressibility with an increasing concentration of the Na,K-ATPase could be related to an increase of the hydration of the liposomes. However, this effect was observed not only at relatively low temperatures at which the hydration shell is highly ordered (and its compressibility is lower in comparison with unbounded water molecules), but also at higher temperatures $\left(\mathrm{T}=38^{\circ} \mathrm{C}\right)$, at which the compressibility of the hydration shell is comparable with the compressibility of surrounding water molecules. This is true at least for zwitterionic phospholipids such are DPPC or DOPC (Hianik et al. 1993). We assume, therefore, that a hydration effect is not predominant in the observed changes of the apparent specific compressibility of the proteoliposomes.

\section{Effect of protein-lipid interactions}

The changes of the reduced apparent specific compressibility of the liposomes, $0.093-0.14 \mathrm{ml} / \mathrm{g}$, which were induced by 
the $\mathrm{Na}, \mathrm{K}-\mathrm{ATPase}$ at its highest concentration (molar ratio ATPase/DOPC $=1: 5250$ ), are comparable with changes of that of liposomes during the phase transition of phospholipids (Halstenberg et al. 1998; Kharakoz and Shlyapnikova 2000). Therefore, the observed changes could be explained by an influence of the enzyme on the structural state of the surrounding phospholipid molecules. Probably, due to interactions between the hydrophobic side of the membrane domain of the Na,K-ATPase and the hydrocarbon chains of the phospholipids, the lipid bilayer becomes more ordered, which is reflected by the decrease of compressibility.

Let us make estimations of the number of lipid molecules whose structural state may be affected by ATPase. This estimation can be based either on the changes in specific volume or apparent specific compressibility. First, we will consider the changes of specific volume. As it is seen from Fig. 2, the specific volume of the lipids decreases with increased ATPase concentrations. Let $\mathrm{Q}$ be any specific physical property (normalized per mass) of a flat lipid membrane containing protein (i.e. specific volume or compressibility). Then, in analogy to Eq. (7), the following equation is approximately valid if the protein has the same thickness as the lipid bilayer

$$
\mathrm{Q}=\mathrm{sQ}_{\mathrm{L}}+(1-\mathrm{s}) \mathrm{Q}_{\mathrm{P}}
$$

where $s$ and $(1-s)$ is the surface fraction occupied by lipid and protein, respectively, $\mathrm{Q}_{\mathrm{L}}$ is average property of the lipid affected by protein and $\mathrm{Q}_{\mathrm{P}}$ is the property of the protein. The number of lipid molecules affected by ATPase can be calculated on the base of specific volume changes as follows. Let $\mathrm{Q}$ is the specific volume, then according to Eq. (8) the average specific volume of the lipid affected by protein is: $\mathrm{Q}_{\mathrm{L}}=\left(\mathrm{Q}-(1-\mathrm{s}) \mathrm{Q}_{\mathrm{P}}\right) / \mathrm{s}$, where $\mathrm{Q}_{\mathrm{P}} \approx 0.73 \mathrm{ml} / \mathrm{g}$ is the specific volume for most proteins (Gekko and Hasegawa 1986). Thus, corresponding $\mathrm{Q}_{\mathrm{L}}$ values are $0.981 \mathrm{ml} / \mathrm{g}$ and $0.960 \mathrm{ml} / \mathrm{g}$ for molar ratios of ATPase/lipid being $1: 52500$ and $1: 5250$, respectively. These values are less than those for pure lipid $(0.999 \mathrm{ml} / \mathrm{g})$. Therefore, the average volume of lipid is reduced by 1.8 and $3.9 \%$, respectively, for above given molar ratios of ATPase/lipid. These changes are comparable with that caused by phase transition of lipids from fluid to solid state, which are approx. 4\% (Marsh 1990). If we assume that a portion of lipids indeed undergoes transition to solid state, then we can calculate the number of such lipid molecules: $\mathrm{N}_{\mathrm{V}}=52500 \times 1.8 / 4=23700$ and $\mathrm{N}_{\mathrm{V}}=5250 \times 3.9 / 4=5120$ for molar ratios ATPase/lipid being $1: 52500$ and $1: 5250$, respectively (see Table 1 ). The coefficient 4 corresponds to the above mentioned maximal changes of the specific volume of phospholipids at phase transition. If we assume, similarly to the findings for the Ca-ATPase, that only one layer of annular phospholipids exists around the $\mathrm{Na}, \mathrm{K}$-ATPase, then approx. 79 annular lipids surround the protein in a lipid bilayer, assuming a cross sectional area of $48.7 \mathrm{~nm}^{2}$ (Hebert et al. 2003). Thus, the obtained values exceed 64-300 times the number of the closest neighbors of a protein molecule.

Similar calculations can be performed also based on the changes of specific apparent compressibility. The intrinsic compressibility of most of the proteins is in the range of 0.2-0.55 ml/g (Kharakoz 2000). Considering that the relative changes of intrinsic compressibility of lipid bilayer is $\Delta \beta / \beta_{0}=$ -0.30 at the transition from fluid to solid state (Halstenberg et al. 1998; Kharakoz and Shlyapnikova 2000) and performing calculations in analogy to that for specific volume, the average number of lipid molecules that undergo a transition to the solid state due to the presence of ATPase will be $\mathrm{N}_{\beta}=$ 8000 and 290 for molar ratios ATPase/lipid being $1: 52500$ and $1: 5250$, respectively (see Table 1 ). Thus, the obtained values exceed 3.7-100 times of the number of annular lipids around one ATPase molecule. These analyses indicate that the ATPase affects the physical properties of a substantially higher number of lipid molecules than that of lipid annulus.

This conclusion is supported also by the fact that the applied method to study liposome compressibility is a macroscopic one, i.e. it does not reflect local effects or the contribution of small structural changes of the bilayer. Considering, that the average diameter of unilamellar liposomes used in this study is about $100 \mathrm{~nm}$ (Apell et al. 1985), then approx. 17 molecules of ATPase are incorporated in one liposome at a molar ratio ATPase/DOPC $=1: 5250$, and the proteolipid complexes composed of an ATPase and its annular lipids occupy only $4 \%$ of the whole liposome surface. So far performed studies indicate, however, that the detected changes of mechanical properties

Table 1. Properties of the lipid bilayers with incorporated Na,K-ATPase

\begin{tabular}{lccccrc}
\hline ATPase/lipid molar ratio & $\begin{array}{c}\varphi_{V} \\
(\mathrm{ml} / \mathrm{g})\end{array}$ & $\begin{array}{c}\varphi_{K} / \beta_{0} \\
(\mathrm{ml} / \mathrm{g})\end{array}$ & $\mathrm{s}_{\mathrm{L}}$ & $\mathrm{s}_{\mathrm{P}}$ & $\mathrm{N}_{\mathrm{V}}$ & $\mathrm{N}_{\beta}$ \\
\hline $0: 1$ & 0.999 & 1.053 & 1.000 & 0 & - & - \\
$1: 52500$ & 0.980 & 1.003 & 0.997 & 0.0027 & 23700 & 8000 \\
$1: 5250$ & 0.954 & 0.942 & 0.973 & 0.0272 & 5120 & 290 \\
\hline
\end{tabular}

Data were calculated on the base of Eq. (8) and using experimental data presented on Fig. 2 and 3 for $\mathrm{T}=25^{\circ} \mathrm{C} . \mathrm{s}_{\mathrm{L}}$ and $\mathrm{s}_{\mathrm{B}}$ fraction of the area occupied by lipid and protein, respectively; $\mathrm{N}_{\mathrm{V}}$ and $\mathrm{N}_{\beta}$, numbers of lipid molecules per 1 molecule ATPase affected by protein calculated according to the specific volume and intrinsic compressibility changes. 
the membranes were significant only when at least $10 \%$ of the membrane area were occupied by an altered structure (Hianik and Passechnik 1995). Moreover, in this study the changes of apparent specific compressibility were observed even at rather low ATPase/DOPC ratio, i.e. at $1: 175000$. In this case not more than 1 ATPase molecule per liposome is expected in the average, and the proteolipid complexes represent only $0.2 \%$ of the liposome area. Similar results were reported earlier for the proteoliposomes containing BR (Hianik et al. 1993) (see Introduction). Therefore, the assumption on the existence of altered membrane regions considerably larger than those created by the ATPases and their annular lipids seems to be realistic.

However, above-mentioned asumption on the rigidization of DOPC molecules induced by ATPase is in contradiction with the current theories of the phase transition in a lipid membrane. Certainly, if we assume that ATPase induced transition of lipids into the solid state, then the correlation length should be approx. 100 diameters of lipid molecules. Such a long correlation seems to be impossible at the experimental condition used in our work. As a matter of fact such a great correlation length could be observed only in immediate vicinity to the phase transition temperature (which is $-20^{\circ} \mathrm{C}$ for the DOPC). As soon as temperature increases, the correlation length is sharply reduced and reaches 1-2 lipid molecules at temperatures several degrees away from the transition point. This behavior of lipid system is well known from both experimental (calorimetry) and theoretical (Monte Carlo simulation) studies published by many authors (see for example Mouritsen et al. 1983; Sperotto and Mouritsen 1991). The temperature at which our experiments were performed exceed the transition point by $30-60^{\circ} \mathrm{C}$.

The question therefore arises why so enormous changes are induced by ATPase and what is the physical mechanisms of this process. Considering the highly accurate determination of specific volume and apparent specific compressibility, we believe that the calculated changes really characterize the system studied. Newertheless, the rather large number of lipid molecules involved in the interaction with $\mathrm{Na}$,K-ATPase is amazing. We are reporting our observation as an interesting experimental phenomenon whose physical mechanism remains unclear for us. It is unlikely that ATPase is able to induce rigidization of DOPC molecules at the temperature substantilly surpassing the phase transition of this lipid. Therefore there should be another physical mechanisms that may explain the observed phenomena. We let this mechanism to be a matter of further studies.

Acknowledgements. This work was supported by INTAS (Project 01-0224), by the Slovak Grant Agency (Project No. 1/0794/10) and by the EU funded project "Development of the Centre of excellence for exploitation of informational macromolecules in the disease prevention and improvement of the quality of life", ITMS: 26240120027, supported by Research \& Development Operational
Programme funded by the ERDF. Author T. H. thanks to prof. D. P. Kharakoz for valuable discussion and advice.

\section{References}

Alpes H., Apell H.-J., Knoll G., Plattner H., Riek R. (1988): Reconstitution of $\mathrm{Na}^{+} / \mathrm{K}^{+}$-ATPase into phosphatidylcholine vesicles by dialysis of nonionic alkyl maltoside detergents. Biochim. Biophys. Acta 946, 379-388

doi:10.1016/0005-2736(88)90413-0

Anner B. M., Robertson J. D., Ting-Beall H. P. (1984): Characterization of $\left(\mathrm{Na}^{+}+\mathrm{K}^{+}\right)$-ATPase liposomes. I. Effect of enzyme concentration and modification on liposome size, intramembrane particle formation and $\mathrm{Na}^{+}, \mathrm{K}^{+}$-transport. Biochim. Biophys. Acta 773, 253-261

doi:10.1016/0005-2736(84)90089-0

Apell H.-J., Marcus M. M., Anner B. M., Oetliker H., Läuger P. (1985): Optical study of active ion transport in lipid vesicles containing reconstituted Na,K-ATPase. J. Membr. Biol. 85, 49-63 doi:10.1007/BF01872005

Cornelius F., Turner N., Christensen H. R. Z. (2003): Modulation of $\mathrm{Na}, \mathrm{K}-\mathrm{ATP}$ ase by phospholipids and cholesterol. II. Steady-state and presteady-state kinetics. Biochemistry 42, 8541-8549 doi:10.1021/bi034532e

Ernst A. M., Contreras F. X., Brügger B., Wieland B. F. (2010): Determinants of specificity at the protein-lipid interface in membranes. FEBS Letters 584, 1713-1720 doi:10.1016/j.febslet.2009.12.060

Esmann M., Marsh D. (2006): Lipid-protein interactions with the Na,KATPase. Chem. Phys. Lipid 141, 94-104 doi:10.1016/j.chemphyslip.2006.02.018

Gekko K., Hasegawa Y. (1986): Compressibility-structure relationship of globular proteins. Biochemislry 253, 6563-6571 doi:10.1021/bi00369a034

Halstenberg S., Heimburg T., Hianik T., Kaatze U., Krivanek R. (1998): Cholesterol-induced variations in the volume and enthalpy fluctuations of lipid bilayers. Biophys. J. 75, 264-271 doi:10.1016/S0006-3495(98)77513-7

Hebert H., Purhonen P., Thomsen K., Vorum H., Maunsbach A. B. (2003): Renal Na,K-ATPase structure from cryo-electron microscopy of two-dimensional crystals. Ann N. Y. Acad. Sci. 986, $9-16$

doi:10.1111/j.1749-6632.2003.tb07132.x

Hianik T., Vozár L. (1985): Mechanical response of bilayer lipid membranes during bacteriorhodopsin conformational changes. Gen. Physiol. Biophys. 4, 331-336

Hianik T., Piknova B., Buckin V. A., Shestimirov V. N., Shnyrov V. L. (1993): Thermodynamics and volume compressibility of phosphatidylcholine liposomes containing bacteriorhodopsin. Progr. Coll. Surface Sci. 93, 150-152

Hianik T., Passechnik V. I. (1995): Bilayer Lipid Membranes: Structure and Mechanical Properties. Kluwer Academic Publishers, Dordrecht

Hianik T., Rybar P., Kostner G. M., Hermetter A. (1997): Molecular acoustic as a new tool for the study of biophysical properties of lipoproteins. Biophys. Chemistry 67, 221-228 doi:10.1016/S0301-4622(97)00041-0 
Hianik T., Haburcak M., Lohner K., Prenner E., Paltauf F., Hermetter A. (1998): Compressibility and density of lipid bilayers composed of polyunsaturated phospholipids and cholesterol. Coll. Surf. A 139, 189-197 doi:10.1016/S0927-7757(98)00280-5

Hianik T., Küpcü S., Sleytr U. B., Rybar P., Krivanek R., Kaatze U. (1999): Interaction of crystalline bacterial cell surface proteins with lipid bilayers in vesicles. Coll. Surf. A 147, 331-339 doi:10.1016/S0927-7757(98)00665-7

Hianik T. Ponikova S., Bagelova J., Antalik M. (2006): Specific volume and compressibility of human serum albumin-polyanion complexes. Bioorg. Med. Chem. Lett. 16, 274-279 doi:10.1016/j.bmcl.2005.10.010

Ivashchuk-Kienbaum Yu. A., Apell H.-J. (1994): Separation and characterization of $\mathrm{Na}^{+}, \mathrm{K}^{+}$-ATPase containing vesicles. Biochim. Biophys. Acta 1196, 29-37 doi:10.1016/0005-2736(94)90291-7

Jørgensen P. L. (1974): Isolation of (Na+ plus K+)-ATPase. Methods. Enzymol. 32, 277-290 doi:10.1016/0076-6879(74)32029-0

Jørgensen P. L., Hakansson K. O., Karlish S. J. D. (2003): Structure and mechanism of Na,K-ATPase: Functional sites and their interactions. Annu Rev. Physiol. 65, 817-849 doi:10.1146/annurev.physiol.65.092101.142558

Karlovská J., Uhríková D., Kučerka N., Teixeira J., Devínsky F., Lacko I., Balgavý P. (2006): Influence of N-dodecyl-N,Ndimethylamine $\mathrm{N}$-oxide on the activity of sarcoplasmic reticulum $\mathrm{Ca}^{2+}$-transporting ATPase reconstituted into diacylphosphatidylcholine vesicles: Effects of bilayer physical parameters. Biophys. Chem. 119, 69-77 doi:10.1016/j.bpc.2005.09.007

Kharakoz D. P. (2000): Protein compressibility, dynamics, and pressure. Biophys. J. 79, 511-525 doi:10.1016/S0006-3495(00)76313-2

Kharakoz D. P., Shlyapnikova A. A. (2000): Thermodynamics and kinetics of the early steps of solid-state nucleation in the fluid lipid bilayer. J. Phys. Chem. B 104, 10368-10378 doi:10.1021/jp001299a

Kratky O., Leopold H., Stabinger H. (1973): The determination of the partial specific volume of proteins by the mechanical oscillator technique. In: Methods in Enzymology. (Ed. E. Grell), vol. 27, pp. 98-110, Academic Press, London

Lee A. G. (2003): Lipid-protein interactions in biological membranes: a structural perspective. Biochim. Biophys. Acta 1612, 1-40 doi:10.1016/S0005-2736(03)00056-7

Lowry O. H., Rosebrough N. G., Farr A. L., Randall R. J. (1951): Protein measurement with the Folin phenol reagent. J. Biol. Chem. 193, 265-272

Marcus M. M., Apell H.-J., Roudna M., Schwendener R. A., Weder H.-G., Läuger P. (1986): $\left(\mathrm{Na}^{+}+\mathrm{K}^{+}\right)$-ATPase in artificial lipid vesicles: influence of lipid structure on pumping rate. Biochim. Biophys. Acta 854, 270-278 doi:10.1016/0005-2736(86)90120-3

Marsh D. (1990): Handbook of Lipid Bilayers. CRC Press, Boca Raton

Marsh D., Horvath L. I. (1998): Structure, dynamics and composition of the lipid-protein interface. Perspectives from spin-labelling. Biochim. Biophys. Acta 1376, 267-296
Mouritsen O. G., Boothroyd A., Harris R., Jan N., Lookman T., MacDonald L., Pink D. A., Zuckerman M. J. (1983): Computer simulation of the main gel-fluid phase transition of lipid bilayers. J. Chem. Phys. 79, 2027-2041 doi:10.1063/1.445987

Olson B. J., Markwell J. (2007): Assays for determination of protein concentration. Curr. Protoc. Protein Sci. 38, 3.4.1-3.4.29

Piknova B., Perochon E., Tocanne J. F. (1993): Hydrophobic mismatch and long-range protein-lipid interactions in bacteriorhodopsin / phosphatidylcholine vesicles. Eur. J. Biochem. 218, 385-396 doi:10.1111/j.1432-1033.1993.tb18388.x

Rehorek M., Dencher N. A., Heyn M. P. (1985): Long range lipidprotein interactions. Evidence from time-resolved fluorescence depolarization and energy transfer experiments with bacteriorhodopsin-dimyristoyl phosphatidylcholine vesicles. Biochemistry 34, 5980-5988 doi:10.1021/bi00342a044

Rybár P., Krivánek R. Samuely T., Lewis R. N., McElhaney R. N., Hianik T. (2007): Study of the interaction of an I-helical transmembrane peptide with phosphatidylcholine bilayer membranes by means of densimetryand ultrasound velocimetry. Biochim. Biophys. Acta 1768, 1466-1478

Sanchez S. A., Tricerri M. A., Ossato G., Gratton E. (2010): Lipid packing determines protein-membrane interactions. Chalenges for apolipoprotein A-I and high density lipoproteins. Biochim. Biophys. Acta 1798, 1399-1408 doi:10.1016/j.bbamem.2010.03.019

Sarvazyan A. P., Kharakoz D. P. (1977): Acoustics study of conformational state of proteins in water. In: Molecular and Cell Biophysics. (Ed. G. M. Frank), pp. 93-106, Nauka, Moscow (in Rusian)

Sarvazyan A. P. (1982): Development of methods of precise measurements in small volumes of liquids. Ultrasonics 20, 151-154 doi:10.1016/0041-624X(82)90032-4

Sarvazyan A. P. (1991): Ultrasonic velocimetry of biological compounds. Annu. Rev. Biophys. Biophys. Chem. 20, 321-342 doi:10.1146/annurev.bb.20.060191.001541

Sarvazyan A. P., Chalikian T. V. (1991): Theoretical analysis of an ultrasonic interferometer for precise measurements at high pressures. Ultrasonics 29, 119-124 doi:10.1016/0041-624X(91)90040-F

Skriver E., Maunsbach A. B., Anner B. M., Jørgensen P. L. (1980): Electron microscopy of phospholipid vesicles reconstituted with purified renal Na,K-ATPase. Cell Biol. Int. Rep. 4, 585-591 doi:10.1016/0309-1651(80)90025-9

Sperotto M. M., Mouritsen O. G. (1991): Monte Carlo simulation studies of lipid order parameter profiles near integral membrane proteins. Biophys. J. 59, 261-270 doi:10.1016/S0006-3495(91)82219-6

Starling A. P., East J. M., Lee A. G. (1995): Effects of phospholipid fatty acyl chain length on phosphorylation and dephosphorylation of the $\mathrm{Ca}(2+)$-ATPase. Biochem. J. 310, 875-879

Toyoshima C., Nakasako M., Nomura H., Ogawa H. (2000): Crystal structure of the calcium pump of sarcoplasmic reticulum at 2.6 A resolution. Nature 405, 647-655 doi: $10.1038 / 35015017$

Received: October 7, 2010

Final version accepted: December 12, 2010 